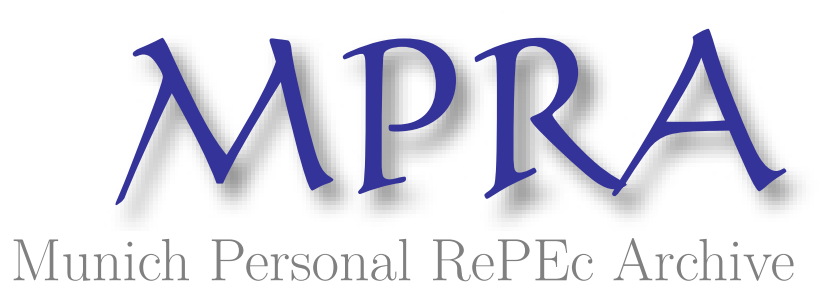

\title{
The Different Impacts of Socio-economic Factors on Suicide between Males and Females
}

yamamura, eiji

6 February 2007

Online at https://mpra.ub.uni-muenchen.de/10175/

MPRA Paper No. 10175, posted 26 Aug 2008 07:58 UTC 


\section{The Different Impacts of Socio-economic Factors on Suicide between Males and Females}

\section{Eiji Yamamura*}

The number of suicides in Japan has substantially increased during its low growth period. The main argument of Durkheim's (1951) seminal work in the field of sociology is that suicide is under influences of not only individual traits but also of the society one belongs to. Recently it was found that the effect of socio-economic variables on suicide rates depends on gender. This paper attempts to examine the difference of socio-economic factors on suicide between males and females.

I used the national panel data of Japan to investigate the determinants of suicide. Based on fixed-effects estimation, by which the year and prefecture-specific unobservable effects can be controlled for, the major findings are twofold. First, the social capital that enhances community integration had a greater effect upon the suicide of females than that of males. This is probably because females are less likely to have full-time jobs and thus have more spare time, leading them to seek social involvement in their neighborhoods and participate in community activities. Second, divorce causes the propensity to commit suicide among males to become about two times higher than that among females due to the compensation costs that males are more likely to pay to females.

\footnotetext{
* Correspondence should be addressed to the author at the Department of Economics, Seinan Gakuin University, 6-2-92 Sawaraku Fukuoka 814-8511, Fukuoka. Japan. E-mail address: yamaei@seinan-gu.ac.jp.
} 


\section{Introduction}

Since Durkheim's (1951) classic analysis of suicide, many researchers in the field of social science have been interested in the factors leading people to commit suicide ${ }^{1}$. According to Durkheim, self-destruction is an individual tragedy as well as a predictable consequence of the degree to which one is integrated into society. On the other hand, Hamermesh and Soss (1974) have asserted theoretically, based upon the concept of individual rationality, that suicide is attributable to expected lifetime utility, which is derived from expected income. To what extent, then, is suicide accounted for by social factors such as social capital, divorce, and marriage, or economic factors such as income and unemployment?

Some studies have argued that social environmental factors have little impact upon suicide (Kunce and Anderson, 2002; Kushner and Sterk, 2005), whereas evidence supporting Durkheim's hypothesis has been provided (Neumayer, 2003). Such a difference appears to be attributable not only to differences in the estimation methods and regression functions employed in each study, but also to a veiled mechanism that should be able to be explained by economics. Bridging the gap between sociological explanations and economical explanations, therefore, will enable us to solve this puzzle of conflicting findings. One of main objectives of the present paper is to provide convincing evidence in support of the validities of both views.

The existing literature takes various factors into account to ascertain the determinants of suicide. By comparing estimation results across the sexes, studies have found through regression analysis not only the similarities but also the differences regarding the determinants of suicide between males and females (Brainerd, 2001; Kunce and Anderson, 2002; Neumayer, 2003; Rodríguez, 2005) ${ }^{2}$. However, even though such studies succeeded in discovering differences across the sexes concerning how people commit suicide, the cause of such differences has not been sufficiently considered. Another issue to be considered here is how to account for this cause from the viewpoint of economics.

1 A number of works in the field of economics attempt to analysis suicide ( e.g., Rodríguez, 2005; Chuang and Huang, 1997; Hamermresh, 1974; Huang, 1996; Marcotte, 2003; Jungeilges and Kirchgassner, 2002; Viren, 1996; Yang and Lester, 1995).

2 Although the recent studies pointed out the importance of age differences in assessing the determinants of suicide (e.g., Rodríguez,2005; Jungeiges and Kirshgassner, 2002), the present study is not able to consider it due to the lack of data which is suitable to this analysis. 
Both time-series and cross section estimations have been conducted previously, but unfortunately such estimation results appear to suffer from omitted variable bias due to unobserved individual specific effects (Hamermesh, 1974; Huang, 1996; Viren, 1996). Recently, a number of studies have attempted to assess the determinants of suicide after controlling for unobservable fixed effects by using panel data (Chuang and Huang, 1997, 2003; Brainerd, 2001; Kunce and Anderson, 2002; Neumayer, 2003; Rodríguez, 2005). Using the national panel data of Japan at the prefectural level, and based upon the fixed effects estimation, in this paper I explore how people commit suicide in Japan ${ }^{3}$.

The organization of this paper is as follows. Section II surveys the socio-economic conditions under which the Japanese live and present a testable hypothesis. Section III presents a concise explanation of the data and specifies the regression functions used to examine the hypothesis. In Section IV, I discuss the results of the estimations. The final section offers concluding observations.

\section{Review of the Socio-economic Situation of Japan}

\section{Suicide and Economic Conditions}

I begin by introducing Figure 1, which illustrates the changes in the number of suicides. As is shown, suicides increased consistently over time, and especially in 1997, when a surprising jump roughly from 23,000 to 31,000 occurred. Relative increases in male suicide are also shown in Figure 2, which illustrates the Male/Female ratio. Turning to Figure 3, which demonstrates the growth rate of Japan's real GDP, it can be seen that the growth rate drops to below zero in 1993, 1997, 1998, and 2001. In particular, the economic depression of 1997 and 1998 seems to have resulted in lowering expected income ${ }^{4}$. Taken together, these results imply that the problem of committing suicide became remarkably serious, especially for males, during the great economic recession period in Japan. Such an imbalance of increases in suicide appears to come from the different impact of various factors between males and females. Therefore, the case of Japan is suitable for examining how committing suicide depends upon gender and differences in the impact of socio-economic factors.

According to Hamermesh and Soss (1974), suicide occurs if lifetime expected

\footnotetext{
3 Although there are a number of empirical works that have studied suicide in Japan (Motohashi, 2001; Motohashi et al., 2004), few scholars in the field of economics have attempted such studies, with the exception of Watanabe et al. (2006).

4 Watanabe et al. (2006) provided evidence that unemployment lead to increases in the Japanese suicide rate in the late 1990s and early 2000s.
} 
utility is sufficiently low. If this is true, then suicide rates can be expected to rise as expected lifetime income falls, under the assumption that expected utility is an increasing function of the degree of expected income. Similarly, I would speculate that the low growth rate experienced in Japan caused more people to commit suicide ${ }^{5}$.

\section{Social and Economic Impact of Divorce}

Consistent increases in divorce are clearly expressed in Figure 4, which shows changes in the number of divorces over time. Durkheim (1951) asserted that divorce reduces family ties, and as a result suicide increases because suicide depends upon social integration, including family ties. Moreover, a number of empirical works have suggested that divorce is positively associated with suicide, supporting the view of Durkheim (Chuang and Huang, 1997; Brainerd, 2001; Nuemayer, 2003, Rodríguez, 2005). If so, then the tendency of increasing suicide rates is partly an outcome of rising divorce rates.

To take an example from the case of Europe (Rodríguez, 2005), it is interesting to note that divorce rates have been found to be positively related to suicide rates for males but not for females. Thus, it is important to investigate further, from the viewpoint of economics, the divorce effects that have not been considered in the existing literature in order to better explore differences in the impact of divorce between males and females. To this end, the amount of compensation paid for divorce according to gender is shown in Table 1. From this, it can be seen that, on the whole, the likelihood that husbands become the payer of compensation is about 8 times that of wives and that this tendency becomes more distinct as the amount of compensation increases. This means that, in addition to the psychological damage caused by the divorce itself, males are more inclined to suffer the economic cost derived from having to pay compensation for the divorce. Looking at Table 1, one can presume that divorce has a larger negative impact on males than on females due to the cost of compensation being more likely borne by males ${ }^{6}$. This implies that the degree of the

\footnotetext{
5 In an analysis of Europe at the country level, Rodríguez (2005) considered the effect of economic inequality on suicide using the Gini coefficient. However, I was unable to construct the panel data of the Gini coefficient at the prefectural level of Japan. This is why it is impossible to assess the effect of economic inequality in the present analysis.

${ }^{6}$ Research of the former Soviet Union did not find a difference in divorce effects across gender upon suicide (Brainerd, 2001). Hypothesis 1 continues to hold, however, in such a case if there is no difference between males and females regarding costs paid in compensation. Hence, it is necessary to compare the actual conditions of the compensation payment across countries in order to verify Hypothesis 1.
} 
effect of divorce on suicide is affected indirectly by the institution of law via the cost of compensation.

Therefore, we postulate Hypothesis 1 about the relationship between divorce and suicide:

Hypothesis 1: Divorce is more likely to cause males to commit suicide than females.

\section{Social Capital}

A cursory examination of Figure 5, which shows changes in the labor participation rates of males and females, reveals that the participation rate of females is distinctly and constantly lower than that of males, despite a slight decline in male participation? It follows from this that the amount of spare time available to females is likely to be larger than that of males and thus that females have more of an inclination to seek companionship and to participate in community activities ${ }^{8}$. If one lives in a tightly knitted community with the members cooperating with each other, one would expect the quality of life to be greater. Inevitably, social capital, which enhances community development (Putnam, 2000), has a greater positive impact on the expected utility of females than on that of males. On the other hand, human relationships in a workplace are more important for males since males are apt to spend longer amounts of time in their workplace ${ }^{9}$. As a consequence, social capital is more negatively associated with the female suicide than male suicide. This means that the effect of social capital depends upon the conditions of labor market.

Correspondingly, we advance the following empirical Hypothesis 2 with respect to the gender differences related to the impact of social capital on suicide.

Hypothesis 2: Social capital is more apt to decrease the likelihood of committing suicide in females than in males if female labor participation rates are lower than those of males.

7 Male participation rates are calculated by dividing the number of households that have working husbands by the total number of households. Female participation rates are calculated by dividing the number of households that have working wives by the total number of households. These data can be obtained every five years. Hence, it is impossible to construct their panel data and use them for regression analysis. 8 Neumayer (2003) hypothesized that female labor participation would be positively associated with suicide because women might be exposed to the stress of both employed work and housework. By using a percentage of females aged 16-64 as a proxy for labor participation, empirical evidence provided support for this prediction (Neumayer, 2003; Rodríguez, 2005). Nonetheless, it seems inappropriate to measure labor participation in such a way because it is dubious that most females aged 16-65 are employed.

9 Although human relationships can be considered to be a kind of social integration stressed by Durkheim, this paper will focus upon social capital within a community. 


\section{Data and Econometric Framework}

Data

Data of the number of suicides come from Ministry of Health, Labor and Welfare (various years). Other data used in the regression estimation as independent variables are collected from Asahi Shinbunsha (various years). The structure of the data is panel, consisting of 47 prefectures and spanning 13 years (1988 - 2001).

Table 2 depicts descriptive statistics for all of the variables used in the regression estimation ${ }^{10}$. From this, the number of male suicides is far larger than the number of female suicides, which is consistent with Figure 2.

\section{Econometric Framework}

Now we would like to formulate the regression function with a view to testing the hypothesis brought up in the preceding section. The estimated function takes the following form:

$$
\begin{aligned}
& \text { SUICID }_{i t}=\alpha_{1} \text { GROW }_{i t o}+\alpha_{2} \text { INCOM }_{i t o}+\alpha_{3} \text { UNEMP }_{i t o}+\alpha_{4} D S C 1_{i t o}+\alpha_{5} D S C 2_{i t o}+ \\
& \quad \alpha_{6} S C_{i t o}+\alpha_{7} D I V O_{i t o}+\alpha_{8} \text { MARRI }_{i t o}+\alpha_{9} \text { HOUSIZ }_{i t o}+\alpha_{10} \text { POP }_{t o}+\alpha_{11} \text { BIRTH }_{i t o} \\
& +\alpha_{12} A L C O L_{i t o}+\varepsilon_{i}+v_{t}+u_{i t},
\end{aligned}
$$

where $S U I C I D_{i t}$ represents the number of suicides in prefecture $i$ and year $t$ to year ${ }^{11}$; $\alpha$ s represents the regression parameters; and $\varepsilon$ represents the individual effects of prefecture. Finally, $v$ represents the year specific effects, while $u$ is an error term. All independent variables are the values of base year to in order to mitigate the endogeneity problem. In addition, special attention must be paid to the omitted variable bias stemming from the unobservable individual specific effects. This can be controlled for by means of fixed effect estimation. Year dummies were also incorporated so as to subdue the conditional and structural changes at the macro level

10 The factors of compensation for divorce and labor participation rate, which are considered in the previous section, should be incorporated as dependent variables in the regression function. However, this is impossible due to the lack of relative data. 11 Most of literature uses suicide rate as a dependent variable (e.g., Rodríguez, 2005; Huang, 1996; Kunce and Anderson, 2002; Neumayer, 2003; Yang and Lester, 1995). In Japan, the suicide rate is measured as the number of suicides per one hundred thousand people. However, suicide rate, for which population is the denominator, seems improper as a dependent variable since the regression function already includes population as an independent variable. Thus, in the present study I use the number of suicides as a dependent variable. 
that could affect the suicide rates.

Variables capturing the economic effects on suicide are GROW, INCOM, UNEMP, standing for the growth rate of real per capita income, real per capita income, and indices of unemployment, respectively. If the improvement of economic conditions reduces suicides by raising the expected utility (Hamermesh and Soss, 1974), then the signs of the former two variables become negative, while that of the later one becomes positive.

To characterize social capital that captures the social integration effects stressed by Durkheim (1951), I used the following independent variables of the base year. The degree to which one is integrated into one's community depends upon the community's condition. According to Putnam (2000), frequent movers have weaker ties within the community, and so mobile communities seem to have less interactivity among neighbors than more stable communities. To put it differently, the more mobile a community is, the weaker the connectedness within it becomes. Hence, DSC 1 and $D S C 2$, denoting the number of population turnovers within a prefecture and the number of immigrants from other prefectures, respectively, can be considered as proxies for the decay of social capital. Accordingly, these coefficients are predicted to take a positive sign.

In traditional Japanese daily life, a public bath was used by community members who, apart from wealthy people, ordinarily lived in houses without a private bath. Through the use of such baths people could get acquainted with neighbors and generate a social network. In modern Japan, most residences have their own baths, and people are therefore more likely to take a bath at home. However, a new type of public bath, which features more deluxe baths and saunas, has recently developed, and these are used by all sectors of society, thus providing a place to meet neighbors and form social capital (Yamamura, 2007). The number of public baths, represented as $S C$, where people contact neighbors to protect people from self-destructive behavior such as suicide, can thus also serve as a proxy for social capital. Therefore, I expect the sign of $S C$ to be negative.

For the purpose of examining causality between divorce and suicide separately for males and females, the number of divorces, represented by DIVO, is used. In addition, the number of marriages, denoted as MARRI, is also incorporated to capture any marital-related influence. Hypothesis 1, raised previously, holds when the coefficient of DIVO takes a positive sign and its value in the case of male suicide is larger than that of female suicide. On the other hand, as suggested in Neumayer (2003), MARRI becomes negative, but this result does not help to explain the gap 
between males and females.

Following previous studies, several control variables are incorporated with the aim of capturing the remaining socio-economic factors. HOUSIZ and POP, representing the average number of members per household and the population, are proxies for the size of households and the prefecture, respectively. Higher average household size can be regarded as having greater potential for feeling happy and having tighter integration within the family, and this would therefore decrease the propensity of committing suicide (Newmayer, 2003). A number of studies have suggested that BIRTH and $A L C O L$, representing birth rate and alcohol consumption, took negative and positive signs, respectively (Brainerd, 2001; Neumayer, 2003; Rodríguez, 2005).

\section{Estimation and Discussion of Empirical Results}

First, I discuss the estimation results based on the previously presented model after controlling for the prefecture fixed effects, as shown in Table 3. Second, in Table 4 , I continue to inquire into the results of the prefecture as well as year fixed effects. The models use both the total and the individual male and female numbers of suicides as dependent variables, for which the estimates are presented in columns (1) and (4), columns (2) and (5), and columns (3) and (6), respectively. These coefficient values stand for the elasticity that enables one to compare the results directly.

I now proceed to study Table 3. Looking at the economic related variables GROW and INCOM reveals that the coefficients were all negative and statistically significant but that INCOM is insignificant from columns (1) to (3). Nonetheless, as shown in columns (4) to (6), INCOM becomes positively significant when GROW is omitted. These results for economic growth but not for level of income are in line with the economic theory of suicide (Hammermesh and Soss, 1974). Moreover, these findings are similar to those of Rodríguez (2005). Coefficients of UNEMP take a negative sign, which is contrary to the prediction.

As for social capital, the coefficients of DSC1 and DSC2 are positive and statistically significant with the exception of DSC2 in column (2). The coefficients of $S C$ almost all take negative signs, and they are significant in columns (3) and (6). Moreover, their absolute values for females are larger than those for males, indicating that the decay of social capital results in committing suicide and that social capital reduces the likelihood of suicide. Such social capital effects are more remarkable for females than for males.

With respect to divorce and marriage, all the coefficients of DIVO and MARRI take 
positive and negative signs and are statistically significant at the $1 \%$ level. This is consistent with the findings of the existing literature (e.g., Brainerd, 2001; Neumayer, 2003). Let us assess this in more detail by comparing the male and female results. The absolute values of DIVO and MARRI for males is larger than that those for females. Specifically, the absolute values of DIVO for males are two times larger than those for females. Further, these differences are distinctly larger for DIVO than for MARRI. In my interpretation of these results, although the effect of marriage is almost the same for both males and females, the impact of divorce is remarkably more serious for males.

Contrary to expectations, the results of HOUSIZ and BIRTH almost all have positive signs. As predicted, all coefficients of $A L C O L$ are positively significant at the $1 \%$ level, which means that alcohol consumption leads to an increase in suicides. In addition, I found that the male alcohol elasticity of suicides is pronouncedly larger than that of females, which is the reverse of what was reported in Brainerd (2001). The alcohol consumption data are for the population rather than individual male and female alcohol consumption, although it seems that most alcohol is consumed by males in Japan. Hence, alcohol consumption is directly related to male suicide but only indirectly related to female suicide. Accordingly, the impact of alcohol consumption will be attenuated for females.

Switching now to Table 4, although GROW and INCOM become statistically insignificant, their signs are unchanged, whereas the sign of UNEMP changes to positive and remains mostly statistically significant, a result in line with the prediction. As a whole, the economic related factors have the predicted effect on suicide.

With respect to social capital, the $D S C 1$ and $D S C 2$ coefficients of females in columns (3) and (6) are positive and statistically significant at the $1 \%$ level. Moreover, the $S C$ coefficients of females take a negative sign and are significant. Their absolute values are distinctly larger than those of males. Table 3 and Table 4 both indicate that these results are robust, implying that the social capital elasticity of suicide for females is larger than for males, strongly supporting the prediction of Hypothesis 2.

Turning now to DIVO and MARRI, all of the coefficients of DIVO and MARRI are positive and negative, respectively, and significant at the $1 \%$ level. Furthermore, the male values of DIVO are two times larger than the female values, meaning that the results are robust with the inclusion of the year dummies. As a whole, the findings shown in Table 3 and Table 4 demonstrate that divorce has a larger negative impact on 
male suicide, a result that strongly upholds Hypothesis 1.

All signs of HOUSIZ changed to negative, a result consistent with the expectations of this study. There is, however, little evidence to statistically support the view of a social integration effect within families, as $P O P$ and $B I R T H$ almost become insignificant. As for $A L C O L$, the coefficients for males continue to be positive and statistically significant, as indicated in columns (2) and (5). Further, the values are remarkably larger than those for females, and the robustness of the results can be seen in Table 3.

Up to this point we have presented various estimated results. Taken together, however, we arrive at the conclusion that the estimation results examined in this section are consistent with both Hypotheses 1 and Hypothesis 2 put forward in the preceding section, with the results supporting them reasonably well.

\section{Concluding Remarks}

The existing literature suggested that the factors that cause people to commit suicide are partly different across the sexes. However, little is known about the reason why such differences exist. The present paper attempts to find the cause of such differences. The economic conditions that females are confronted with differ from those faced by males in Japan. The significant point here is that the effects of social capital on suicide are influenced by various economic conditions.

Up to this point, by first interpreting the descriptive tables and the figures, I have outlined the finding that various economic conditions are different between males and females with regard, for example, to the compensation costs for divorce or labor participation rates. Next, through fixed effects estimation to control for unobservable individual and year specific effects, I have compared the effects of the economic and social factors that are different between males and females with respect to suicide.

Concisely, this study provides the following major findings:

(1) Males are much more likely to bear the burden of compensation payments for divorce than females. Since divorce has a more negative impact on males than females through this compensation cost, divorce is more likely to cause males to commit suicide than females.

(2) Female labor participation rates are lower than those of males, and as a result females have more spare time to spend with neighbors than do males. Accordingly, social capital is more apt to decrease the likelihood of committing suicide in females than in males.

The evidence provided in the present paper suggests that when planning 
community-based suicide prevention programs, the various economic conditions in which individuals are situated should be considered ${ }^{12}$. The results of the investigations in this study can serve as information and advice for the direction of such policies for suicide prevention. In addition, it is necessary to relate suicide and labor market conditions separately for males and females in order to reinforce the conclusions of this paper. A foreseeable extension of this research would compare these differences across generations. Furthermore, it is also important to use data at the individual level to study the mechanism of suicide more precisely, or, as another possibility, cross country data could be collected to compare institutional effects, such as laws, on suicide.

12 Motohashi et al. (2004) introduced community-based suicide prevention programs in Akita Prefecture, Japan. 


\section{References}

Asahi Shinbunsha. (various years). Minryoku: TODOFUKEN-BETSU MINRYOKU SOKUTEI SHIRYOSHU. Tokyo: Asahi-Shinbunsha.

Baltagi, B. (2005) Econometric Analysis of Panel Data. West Sussex: John Wiley and Sons.

Brainerd, E. (2001). Economic reform and mortality in the former Soviet Union: A study of the suicide epidemic in the 1990s, European Economic Review, 45, 1007-19.

Cabinet office, Government of Japan (various years) Kokumin Keizai keisan nenpo. Tokyo: Naikaku-fu.

Chuang, Lin, H., and Huang, W.C. (1997). Economic and social correlates of regional suicide rates: A pooled cross-section and time-series analysis, Journal of Socio-Economics, 26, 277-89.

Durkheim, E. (1951). Suicide: A study in sociology. Translated by. J. A. Spaulding and G. Simpson. Gencoe, IL: Fee Press.

Hamermersh, D, S. (1974). The economics of black suicide, Southern Economic Journal, 41, 188-99.

Hamermersh, D, S., and Soss, N,M. (1974). An economic theory of suicide, Journal of Political Economy, 82, 83-98.

Huang, W,C. (1996). Religion, culture, economic and sociological correlates of suicide rates: a cross-national analysis, Applied Economics Letters, 3, 779-82.

Jungeilges, J. and Kirchgassner, G. (2002). Economic welfare, civil liberty, and suicide: an empirical investigation, Journal of Socio-Economics, 31, 215-31.

Kunce, M. and Anderson,A.L. (2002). The impact of socioeconomic factors on state suicide rates: A methodological note, Urban Studies, 39, 155-62.

Kushner, H. I., and Sterk, C.E. (2005). The limits of social capital: Durkheim, Suicide, 
and social cohesion, American Journal of Public Health, 95, 1139-43.

Marcotte, D. E. (2003). The economics of suicide, Revisited, Southern Economic Journal, 69, 2769-76.

Ministry of Health, Labor and Welfare. (various years). Jinko Dotai Tokei Tokushu Hokoku. Tokyo: Ministry of Health, Labor and Welfare.

Motohashi, Y. (1991). Effects of Socioeconomic Factors on Secular Trends in Suicide in Japan: 1953-1986, Journal of Biosocial Science, 23, 221-227.

Motohashi, Y., Kaneko, Y., and Sasaki, H. (2004). Community-Based Suicide Prevention Program in Japan Using a Health Promotion Approach, Health and Preventive Medicine, 9, 3-8.

Neumayer E. (2003). Socioeconomic factors and suicide rates at large unit aggregate levels: A comment, Urban Studies, 40, 276

Putnam, R. (2000). Bowling Alone: The Collapse and Revival of American Community. New York: A Touchstone Book.

Rodríguez, A. (2005). Income inequality, unemployment, and suicide: a panel data analysis of 15 European countries, Applied Economics, 37, 439-51.

Viren, M. (1996). Suicide and business cycles: Finnish evidence, Applied Economics Letters, 3, 737-38.

Watanabe, R., Furukawa, M. and Nakamura.R, and Ogura, Y. (2006). Analysis of the Socioeconomic Difficulties affecting the Suicide Rate in Japan. KIER Discussion Paper Series No. 626.

Yamamura, E. (2007). Diffusion of Home Computers and Social Networks: A Study using Japanese Panel Data, Forthcoming in Applied Economics Letters.

Yang, B. (1992). The economy and suicide: A time-series study of the U.S.A, American Journal of Economics and Sociology, 51, 87-99.

Yang, B., Sark.S, and Lester, D. (1992). Suicide and unemployment: predicting the smoothed trend and yearly fluctuations, Journal of Socio-Economics, 21, 39-41.

Yang, B, and Lester, D. (1995). Suicide, homicide and unemployment, Applied Economics Letters, 2, 278-79. 


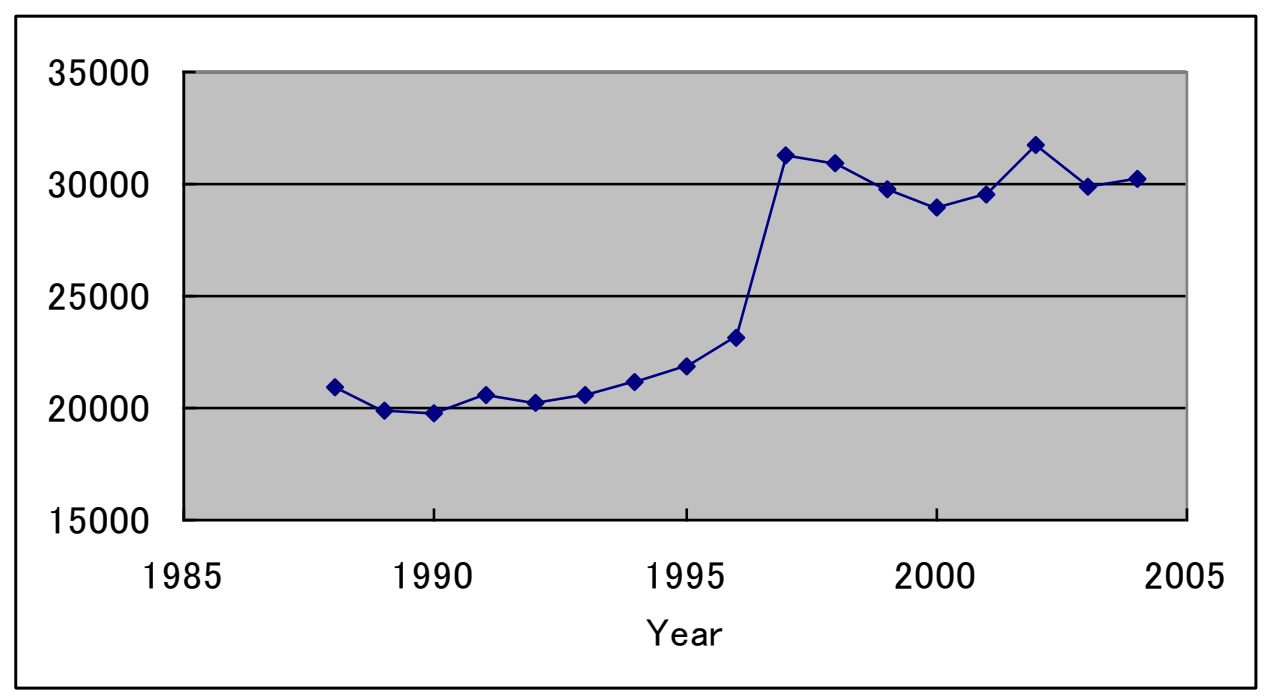

Fig 1. Number of Suicides.

Sources: Ministry of Health, Labor and Welfare (various years) Jinko Dotai Tokei Tokushu Hokoku. 


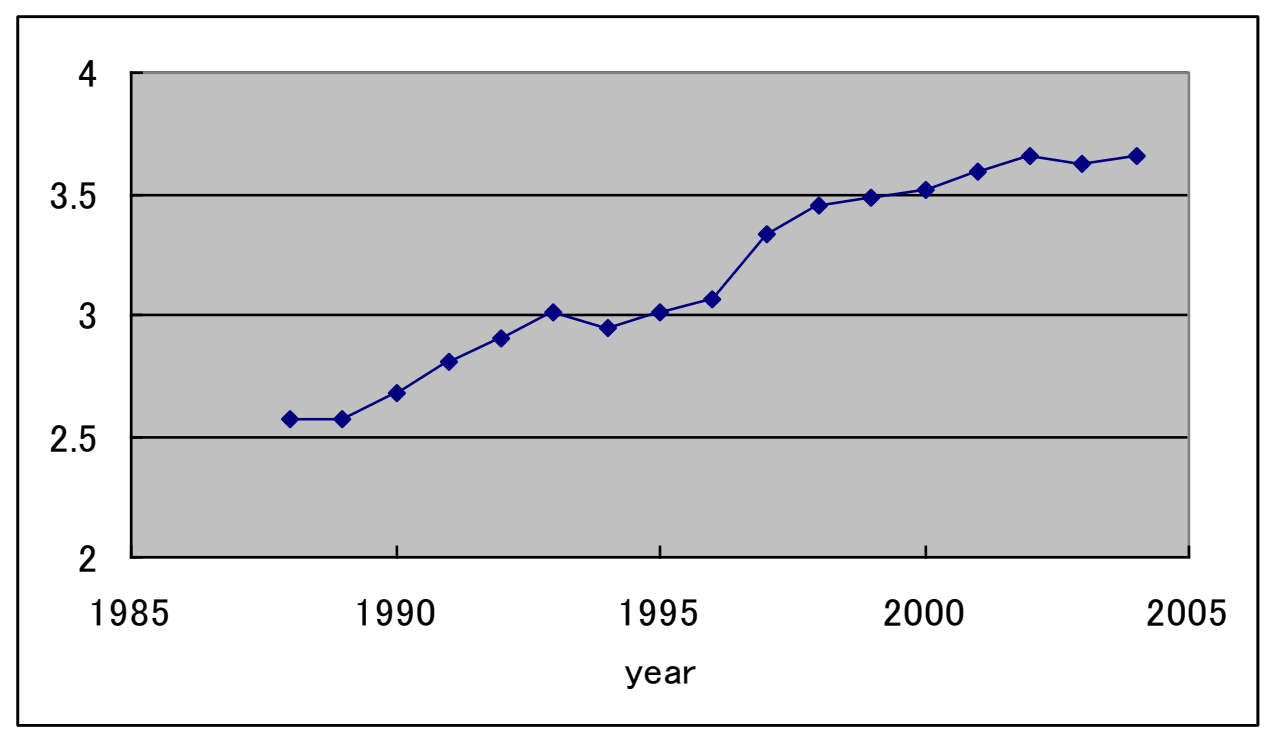

Fig 2. Male/Female Ratio.

Sources: Ministry of Health, Labor and Welfare (various years) Jinko Dotai Tokei Tokushu Hokoku. 


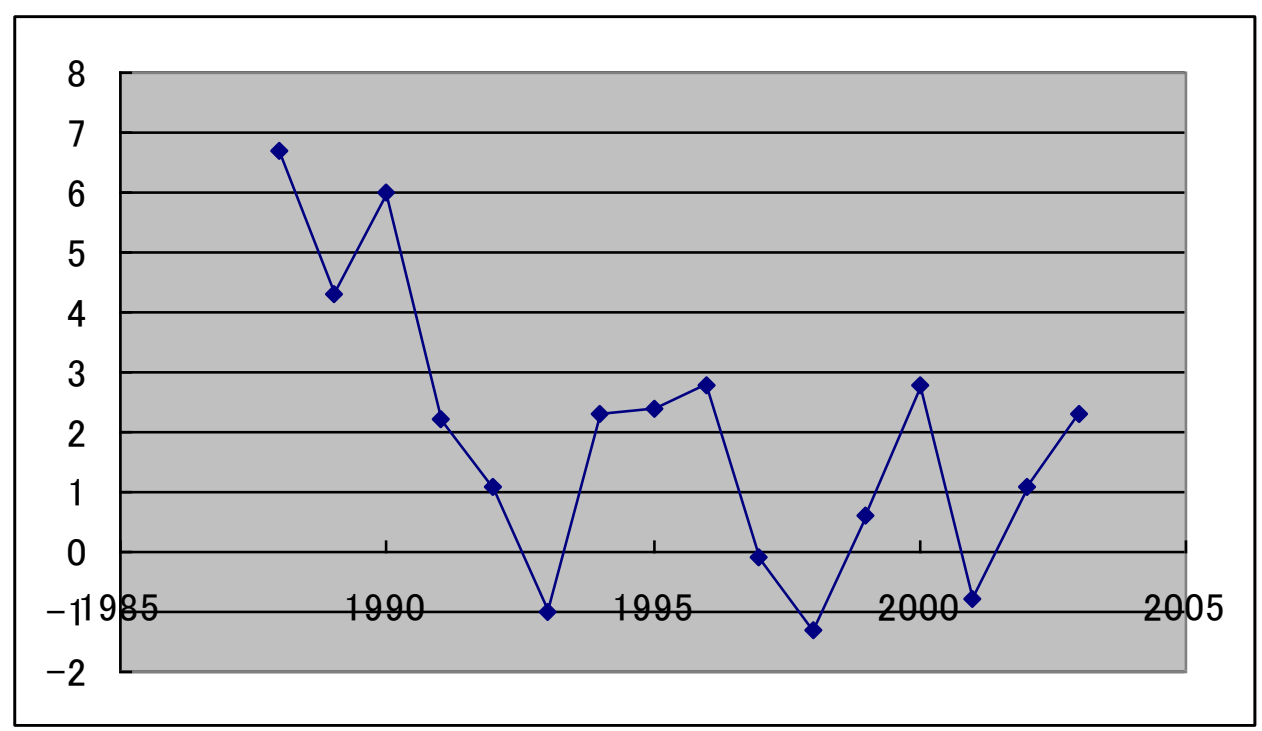

Fig 3. Growth Rate of Real GDP.

Sources: Cabinet Office, Government of Japan (various years) Kokumin Keizai Keisan Nenpo. 


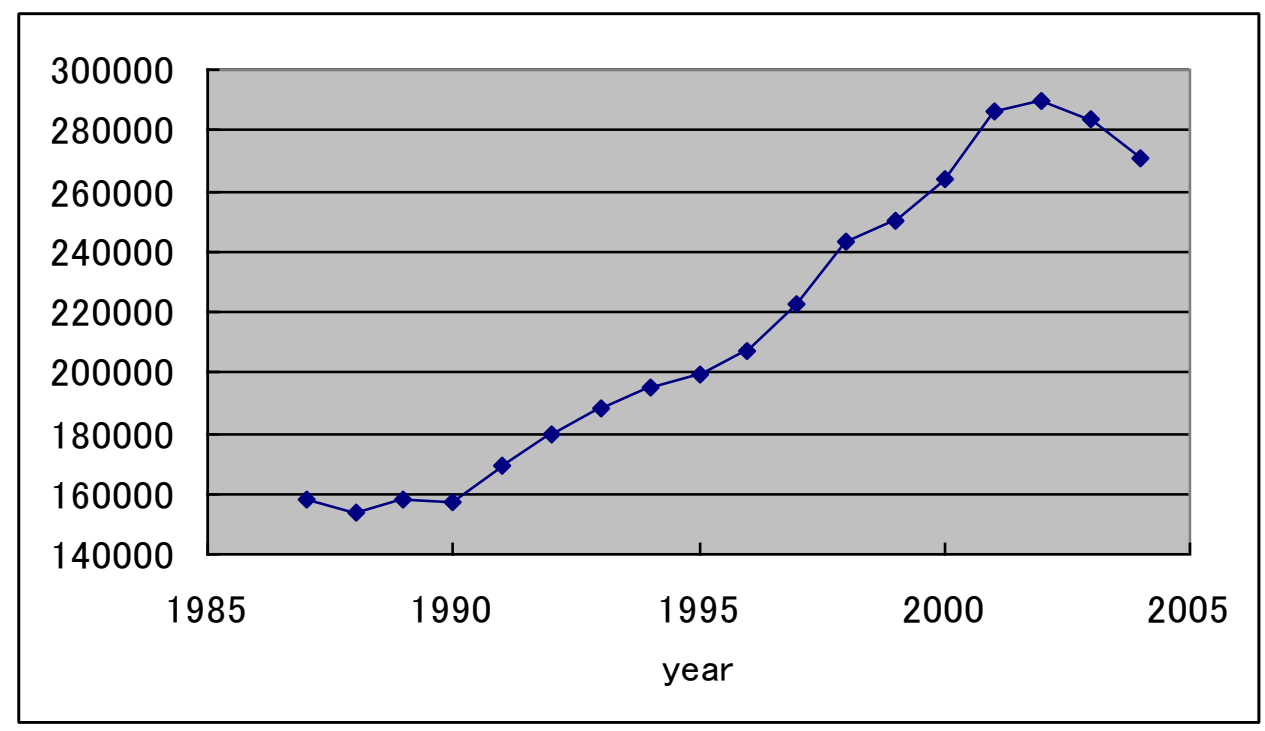

Fig 4. Number of Divorces.

Sources: Asahi Shinbunsha. (various yeas). Minryoku: TODOFUKEN-BETSU MINRYOKU SOKUTEI SHIRYOSHU. Tokyo: Asahi-Shinbunsha. 


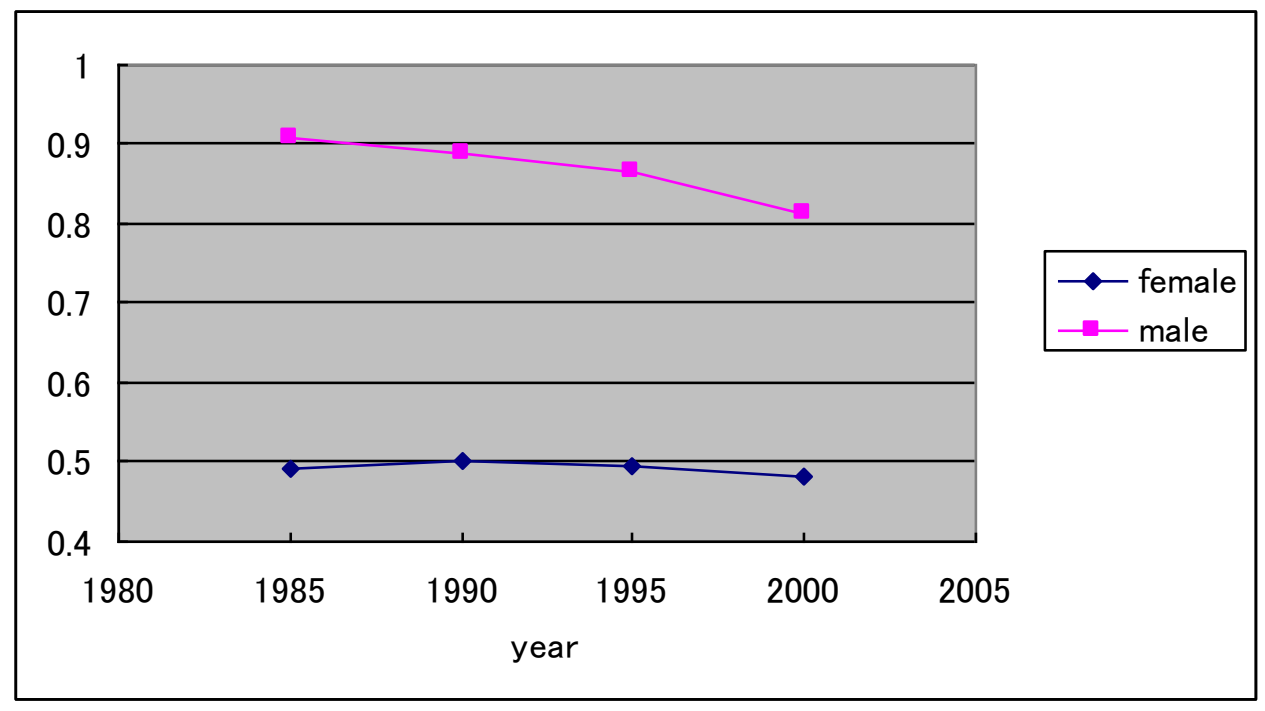

Fig 5. Labor Participation Rate.

Sources: Asahi Shinbunsha (various yeas). Minryoku: TODOFUKEN-BETSU MINRYOKU SOKUTEI SHIRYOSHU. Tokyo: Asahi-Shinbunsha.

Note: Male participation rates are calculated by dividing the number of households that have working husbands by the total number of households. Female participation rates are calculated by dividing the number of households that have working wives by the total number of households. 
Table 1. Amount of Divorce Compensation.

\begin{tabular}{l|llllllll}
\hline Payer & Total & $\sim 1$ & 1million & 2 & 4 & 6 & 10 & 20 \\
& & million & -2 & million & million & million & million & million \\
& & & million & $\sim 4$ & $\sim 6$ & $\sim 10$ & $\sim 20$ & \\
& & & & million & million & million & million & \\
Total & 8,604 & 2,258 & 1,229 & 1,434 & 746 & 786 & 536 & 269 \\
Husband & 7,694 & 2,022 & 1,150 & 1,327 & 690 & 711 & 502 & 260 \\
Wife & 910 & 236 & 149 & 107 & 56 & 75 & 33 & 9 \\
\hline
\end{tabular}

Sources: Shiho Tokei Nenpo (2005). Data source:

http://www.rikon-navi.jp/shiryou/genjyou/price.html. 
Table 2. Descriptive Statistics.

\begin{tabular}{|c|c|c|c|}
\hline Variables & Definition & Mean & Std. Dev \\
\hline SUICID & Total number of suicides & 525 & 459 \\
\hline MSUICID & Number of male suicides & 357 & 321 \\
\hline FSUICID & Number of female suicides & 167 & 141 \\
\hline GROW & Growth rate of real per capita income & 0.005 & 0.03 \\
\hline INCOM & Real per capita income ${ }^{\text {a }}$ & 2,838 & 408 \\
\hline UNEMP & Indices of unemployment (the standard value is 100 ) & 99.4 & 32.4 \\
\hline DSC1 & Number of population turnovers within prefecture ${ }^{b}$ & 63.6 & 79.7 \\
\hline DSC2 & Number of immigrants from other prefectures ${ }^{b}$ & 71.9 & 85.8 \\
\hline $\mathrm{SC}$ & Number of public baths & 549 & 521 \\
\hline DIVO & Number of divorces & 4,486 & 4,931 \\
\hline MARRI & Number of marriages & 16,276 & 17,158 \\
\hline HOUSIZ & Average members of household & 5.2 & 3.4 \\
\hline POP & Total population ${ }^{b}$ & 2,648 & 2,393 \\
\hline BIRTH & Birth rate & 0.09 & 0.009 \\
\hline ALCOL & Alcohol consumption a & 121,207 & 118,169 \\
\hline
\end{tabular}

Source: Ministry of Health, Labor and Welfare (various years) Jinko Dotai Tokei Tokushu Hokoku.

Asahi Shinbunsha (various yeas). Minryoku: TODOFUKEN-BETSU MINRYOKU SOKUTEI SHIRYOSHU. Tokyo: Asahi-Shinbunsha. 
Table 3. Regression Results on Suicide (Fixed Effects Model).

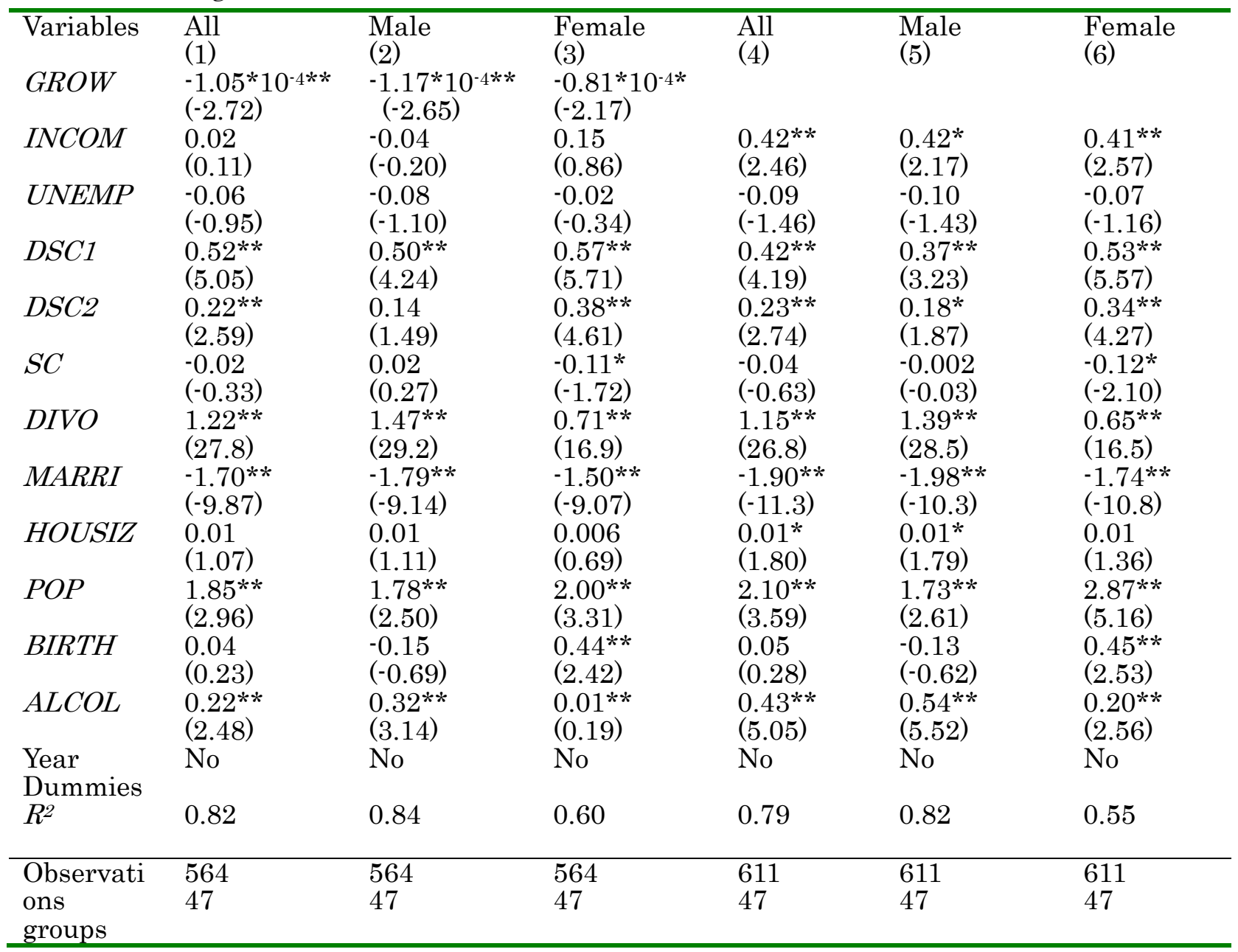

Notes: Numbers are elasticity calculated by the delta method. Numbers in

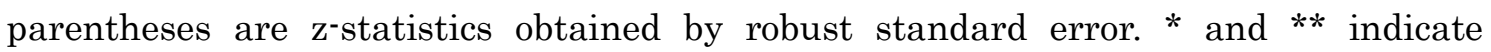
significance at 5 and 1 per cent levels, respectively (one-sided tests). 
Table 4. Regression Results on Suicide (Fixed Effects Model).

\begin{tabular}{|c|c|c|c|c|c|c|}
\hline Variables & $\begin{array}{l}\text { All } \\
\text { (1) }\end{array}$ & $\begin{array}{l}\text { Male } \\
\text { (2) }\end{array}$ & $\begin{array}{l}\text { Female } \\
\text { (3) }\end{array}$ & $\begin{array}{l}\text { All } \\
\text { (4) }\end{array}$ & $\begin{array}{l}\text { Male } \\
\text { (5) }\end{array}$ & $\begin{array}{l}\text { Female } \\
\text { (6) }\end{array}$ \\
\hline GROW & $\begin{array}{l}0.21^{*} 10^{-4} \\
(0.56)\end{array}$ & $\begin{array}{l}0.29 * 10^{-4} \\
(0.64)\end{array}$ & $\begin{array}{l}0.06^{*} 10^{-4} \\
(0.17)\end{array}$ & & & \\
\hline$I N C O M$ & $\begin{array}{l}0.27 \\
(1.36)\end{array}$ & $\begin{array}{l}0.26 \\
(1.11)\end{array}$ & $\begin{array}{l}0.30 \\
(1.44)\end{array}$ & $\begin{array}{l}0.22 \\
(1.31)\end{array}$ & $\begin{array}{l}0.21 \\
(1.07)\end{array}$ & $\begin{array}{l}0.35 \\
(1.42)\end{array}$ \\
\hline UNEMP & $\begin{array}{l}0.12^{*} \\
(2.08)\end{array}$ & $\begin{array}{l}0.12^{*} \\
(1.76)\end{array}$ & $\begin{array}{l}0.12^{*} \\
(2.06)\end{array}$ & $\begin{array}{l}0.12^{*} \\
(2.07)\end{array}$ & $\begin{array}{l}0.13^{*} \\
(1.95)\end{array}$ & $\begin{array}{l}0.09 \\
(1.16)\end{array}$ \\
\hline$D S C 1$ & $\begin{array}{l}0.34^{* *} \\
(3.90)\end{array}$ & $\begin{array}{l}0.28^{* * *} \\
(2.79)\end{array}$ & $\begin{array}{l}0.46^{* *} \\
(5.07)\end{array}$ & $\begin{array}{l}0.25^{* *} \\
(2.98)\end{array}$ & $\begin{array}{l}0.16^{*} \\
(1.69)\end{array}$ & $\begin{array}{l}0.43^{* *} \\
(4.99)\end{array}$ \\
\hline$D S C 2$ & $\begin{array}{l}0.10 \\
(1.48)\end{array}$ & $\begin{array}{l}0.04 \\
(0.48)\end{array}$ & $\begin{array}{l}0.24^{* *} \\
(3.27)\end{array}$ & $\begin{array}{l}0.14^{*} \\
(1.97)\end{array}$ & $\begin{array}{l}0.10 \\
(1.22)\end{array}$ & $\begin{array}{l}0.23^{* *} \\
(3.08)\end{array}$ \\
\hline$S C$ & $\begin{array}{l}-0.08 \\
(-1.28)\end{array}$ & $\begin{array}{l}-0.05 \\
(-0.71)\end{array}$ & $\begin{array}{l}-0.14^{*} \\
(-2.13)\end{array}$ & $\begin{array}{l}-0.11^{*} \\
(-1.98)\end{array}$ & $\begin{array}{l}-0.09 \\
(-1.34)\end{array}$ & $\begin{array}{l}-0.17^{* *} \\
(-2.80)\end{array}$ \\
\hline DIVO & $\begin{array}{l}1.17^{* * *} \\
(23.8)\end{array}$ & $\begin{array}{l}1.39^{* * *} \\
(24.3)\end{array}$ & $\begin{array}{l}0.70 * * \\
(13.7)\end{array}$ & $\begin{array}{l}1.04^{* *} \\
(22.3)\end{array}$ & $\begin{array}{l}1.25^{* *} \\
(23.2)\end{array}$ & $\begin{array}{l}0.59^{* * *} \\
(123)\end{array}$ \\
\hline$M A R R I$ & $\begin{array}{l}-1.16^{* *} \\
(-7.38)\end{array}$ & $\begin{array}{l}-1.22^{* *} \\
(-6.66)\end{array}$ & $\begin{array}{l}-1.04^{* *} \\
(-6.36)\end{array}$ & $\begin{array}{l}-1.29 * * \\
(-8.36)\end{array}$ & $\begin{array}{l}-1.30 * * \\
(-7.32)\end{array}$ & $\begin{array}{l}-1.25^{* *} \\
(-7.87)\end{array}$ \\
\hline HOUSIZ & $\begin{array}{l}-0.06 \\
(-0.73)\end{array}$ & $\begin{array}{l}-0.06 \\
(-0.65)\end{array}$ & $\begin{array}{l}-0.06 \\
(-0.66)\end{array}$ & $\begin{array}{l}-0.11 \\
(-1.27)\end{array}$ & $\begin{array}{l}-0.12 \\
(-1.19)\end{array}$ & $\begin{array}{l}-0.09 \\
(-1.00)\end{array}$ \\
\hline$P O P$ & $\begin{array}{l}0.57 \\
(1.04)\end{array}$ & $\begin{array}{l}0.33 \\
(0.51)\end{array}$ & $\begin{array}{l}1.08^{*} \\
(1.88)\end{array}$ & $\begin{array}{l}0.78 \\
(1.52)\end{array}$ & $\begin{array}{l}0.20 \\
(0.35)\end{array}$ & $\begin{array}{l}2.01^{* *} \\
(3.77)\end{array}$ \\
\hline BIRTH & $\begin{array}{l}0.15 \\
(0.70)\end{array}$ & $\begin{array}{l}0.13 \\
(0.54)\end{array}$ & $\begin{array}{l}0.18 \\
(0.80)\end{array}$ & $\begin{array}{l}0.18 \\
(0.87)\end{array}$ & $\begin{array}{l}0.17 \\
(0.70)\end{array}$ & $\begin{array}{l}0.22 \\
(0.98)\end{array}$ \\
\hline$A L C O L$ & $\begin{array}{l}0.14 \\
(1.64)\end{array}$ & $\begin{array}{l}0.21 * \\
(2.11)\end{array}$ & $\begin{array}{l}-0.005 \\
(-0.06)\end{array}$ & $\begin{array}{l}0.28^{* *} \\
(3.44)\end{array}$ & $\begin{array}{l}0.33^{* *} \\
(3.57)\end{array}$ & $\begin{array}{l}0.16^{*} \\
(1.91)\end{array}$ \\
\hline $\begin{array}{l}\text { Year } \\
\text { Dummies }\end{array}$ & Yes & Yes & Yes & Yes & Yes & Yes \\
\hline & 0.88 & 0.89 & 0.71 & 0.87 & 0.88 & 0.67 \\
\hline $\begin{array}{l}\text { Observations } \\
\text { groups }\end{array}$ & $\begin{array}{l}564 \\
47 \\
\end{array}$ & $\begin{array}{l}564 \\
47 \\
\end{array}$ & $\begin{array}{l}564 \\
47 \\
\end{array}$ & $\begin{array}{l}611 \\
47 \\
\end{array}$ & $\begin{array}{l}611 \\
47 \\
\end{array}$ & $\begin{array}{l}611 \\
47 \\
\end{array}$ \\
\hline
\end{tabular}

